\title{
Current Role of Cardiac and Extra-Cardiac Pathologies in Clinically Indicated Cardiac Computed Tomography with Emphasis on Status Before Pulmonary Vein Isolation
}

\author{
Kardiale und extra-kardiale pathologische Befunde in \\ klinisch indizierter Computertomografie bei Patienten \\ vor Pulmonalvenen-Isolation
}

Authors

Affiliations
J. M. Sohns ${ }^{1,4}$, J. Menke1, W. Staab ${ }^{1}$, J. Spiro², M. Fasshauer ${ }^{1}$, J. T. Kowallick¹, L. Bergau ${ }^{3}$, P. A. Zwaka', C. Unterberg-Buchwald ${ }^{3}$, J. Lotz ${ }^{1,4}$, A. Schwarz ${ }^{1}$

\author{
Institute for Diagnostic and Interventional Radiology, University Medical Center of Georg-August-University, Goettingen \\ Radiology, University Hospital of Cologne \\ Cardiology and Pneumology, University Medical Center of Georg-August-University, Goettingen \\ DZHK, German Center for Cardiovascular Research, partner site Goettingen
}

\author{
Key words \\ - cardiac \\ - CT angiography \\ - angiography \\ - thorax \\ - mediastinum \\ - cost-effectiveness
}

received 11.9.2013

accepted 6.1.2014

Bibliography

Dol http://dx.doi.org/

10.1055/s-0034-1366107

Published online: 19.3.2014

Fortschr Röntgenstr 2014; 186: 860-867 @ Georg Thieme Verlag KG Stuttgart - New York . ISSN 1438-9029

\section{Correspondence \\ Dr. Jan M. Sohns}

Institute for Diagnostic and Interventional Radiology, DZHK, University Hospital Goettingen Robert-Koch-Str. 40 37075 Goettingen Germany

Tel.: ++49/5 51/398965

Fax: ++49/5 51/39 9606

jan.sohns@med.uni-

goettingen.de

\section{Zusammenfassung}

$\nabla$

Ziele: In dieser Studie wurde bei Patienten mit Vorhofflimmern die Inzidenz von kardialen und signifikanten extra-kardialen Befunden im CT vor Pulmonalvenen-Isolation untersucht.

Material und Methoden: 224 Patienten (64 \pm 10 Jahre; männlich 63\%) mit Vorhofflimmern wurden vor PVI mit einer kardialen 64-Zeilen CT untersucht. Extra-kardiale Befunde wurden als „signifikant“ bezeichnet, wenn zusätzliche Untersuchungen oder Therapien empfohlen wurden; andernfalls wurden sie als „nicht signifikant“ bezeichnet. Die kardialen Befunde wurden ebenfalls ausgewertet. Die Befunde waren dem analysierenden Kardiologen und Radiologen vor dem CT unbekannt. Zusätzlich wurden Kosten für anschließende Bildgebungen ausgewertet, die zur Verifikation von möglichen pathologischen Befunden erforderlich waren.

Ergebnisse: Insgesamt wurden 724 kardiale Befunde bei 203 Patienten detektiert (91\% der Patienten). Zusätzlich wurden 619 extra-kardiale Befunde in 179 Patienten gefunden $(80 \%$ der Patienten). Bei diesen extra-kardialen Befunden waren 196 (32\%) „signifikant“ und 423 (68\%) „nicht signifikant“. Bei 2 Patienten (1\%) zeigten sich maligne Befunde, die vorher nicht bekannt waren (Ösophaguskarzinom und Bronchialkarzinom). 203 weiterführende bildgebende Untersuchungen folgten den primär detektierten Befunden im ersten CT, um die signifikanten extra-kardialen Befunde zu verifizieren (124 zusätzliche CT, Kosten 38314,69 US Dollar). Insgesamt kamen auf einen untersuchten Patienten 3,2 kardiale und 2,8 extrakardiale Befunde. Extra-kardiale Befunde kamen signifikant häufiger vor bei Patienten über 60 Jahren, Rauchern und Patienten mit einem kardialen pathologischen Befund $(\mathrm{p}<0,05)$.

Schlussfolgerungen: Kardiale CT Untersuchungen vor Pulmonalvenen-Isolation sollten auf extrakardiale Nebenbefunde untersucht werden, da di-

\section{Abstract \\ V}

Purpose: The aim of this study was to assess the incidence of cardiac and significant extra-cardiac findings in clinical computed tomography of the heart in patients with atrial fibrillation before pulmonary vein isolation (PVI).

Materials and Methods: 224 patients $(64 \pm 10$ years; male $63 \%$ ) with atrial fibrillation were examined by cardiac 64-slice multidetector CT before PVI. Extra-cardiac findings were classified as "significant" if they were recommended to additional diagnostics or therapy, and otherwise as "non-significant". Additionally, cardiac findings were documented in detail.

Results: A total of 724 cardiac findings were identified in 203 patients ( $91 \%$ of patients). Additionally, a total of 619 extra-cardiac findings were identified in 179 patients ( $80 \%$ of patients). Among these extra-cardiac findings 196 (32\%) were "significant", and 423 (68\%) were "nonsignificant". In 2 patients ( $1 \%$ ) a previously unknown malignancy was detected (esophageal cancer and lung cancer, local stage, no metastasis). 203 additional imaging diagnostics followed to clarify the "significant" findings (124 additional CT, costs 38314.69 US dollars). Overall, there were 3.2 cardiac and 2.8 extra-cardiac findings per patient. Extra-cardiac findings appear significantly more frequently in patients over 60 years old, in smokers and in patients with a history of cardiac findings $(\mathrm{p}<0.05)$.

Conclusion: Cardiac CT scans before PVI should be screened for extracardiac incidental findings that could have important clinical implications for each patient.

Key points:

- Cardiac and extra-cardiac findings are common in patients with an indication for pulmonary vein isolation on previous CT scans.

- Malignancies can be detected in $1 \%$ of all patients. 
ese für die Patienten relevant sein können, wie beispielweise die Detektion von Malignomen.

Kernaussagen:

- Kardiale und extra-kardiale Befunde treten bei Patienten mit der Indikation zur Pulmonalvenen-Isolation relativ häufig auf.

- Bei 2 Patienten (1\%) zeigten sich maligne Befunde, die vorher nicht bekannt waren (Ösophaguskarzinom und Bronchialkarzinom ohne Metastasierung).

- Unter den extra-kardialen Befunden fanden sich 196 (32\%) die als „signifikant“ bezeichnet wurden und die teils für die Patienten klinisch relevant waren.
- $32 \%$ of all extra-cardiac findings can be of significant relevance with consequences for patients.

- Altogether, there are 3.2 cardiac and 2.8 extra-cardiac findings in patients with indication for pulmonary vein isolation and $\mathrm{CT}$.

- Extra-cardiac findings appear significantly more frequently in patients over 60 years old, in smokers and in patients with a history of cardiac findings ( $\mathrm{p}<0.05)$.

Citation Format:

- Sohns JM, Menke J, Staab W et al. Current Role of Cardiac and Extra-Cardiac Pathologies in Clinically Indicated Cardiac Computed Tomography with Emphasis on Status Before Pulmonary Vein Isolation. Fortschr Röntgenstr 2014; 186: 860-867

\section{Introduction}

$\nabla$

Cardiac computed tomography (CT) including coronary CT angiography is applied for several clinical indications. Specifically the exclusion of significant coronary artery stenosis ( $\geq 50 \%$ luminal reduction) is becoming a major indication in patients with a low to intermediate risk of coronary artery disease [1, 2]. Atrial and ventricular anatomy can be evaluated comprehensively [3, 4]. Cardiac CT before pulmonary vein isolation (PVI) in patients with atrial fibrillation is useful and is regularly performed for evaluating the anatomy of pulmonary veins and left atrium for optimized procedure planning or three-dimensional mapping $[5,6]$. When clinically indicated, CT may be used in a triple-ruleout strategy to exclude aortic dissection and pulmonary embolism in addition to cardiac pathology [7-9].

In the patient's interest all relevant information from cardiac CT imaging should be utilized. This requires assessing not only the heart, but also all surrounding structures that were imaged during the CT scan. According to other authors, the incidence of extra-cardiac findings at cardiac CT ranged from $8 \%$ in asymptomatic patients [10] to $58 \%$ in symptomatic patients with known or suspected coronary artery disease (CAD), and up to $22 \%$ if the patients had clinically significant findings that required at least a follow-up [11]. Schietinger et al. reported extra-cardiac incidental findings even in $69 \%$ of patients who were scanned prior to pulmonary vein isolation [12]. Most previous studies about cardiac CT concentrated on either cardiac findings or incidental extra-cardiac findings and did not evaluate the cost of subsequent diagnostics $[10,11,13,14]$.

The purpose of this retrospective study was to jointly assess cardiac and extra-cardiac findings in patients undergoing clinically indicated cardiac CT due to atrial fibrillation and pulmonary vein isolation, and to determine the implications of the extra-cardiac findings for patient management.

\section{Materials and Methods}

\section{Study population}

Between February 2009 and September 2011, cardiac CT was performed in 224 consecutive patients for pulmonary vein isolation with atrial fibrillation ( $n=220$ cases $1-2$ days before intervention, $\mathrm{n}=4$ cases 1 day after). All cardiac CT scans had diagnostic image quality. For this retrospective study the patients were identified using the local digital patient database and radiological information system (RIS) during the study period. The follow-up period ranged from about 1 year for the latest CT scan to about
3 years for the first CT scan and included searching for additional imaging, continuing the patient history, and collecting existing histopathological reports. Informed consent had been obtained from each patient for the CT scan and for study evaluations. This study was in consensus with the Declaration of Helsinki and was approved by the local Ethics Committee.

\section{Cardiac CT scan protocol and image reconstruction}

All cardiac CTs were performed with a 64-row multi-detector CT (VCT Light Speed, GE Healthcare, Milwaukee, USA) and retrospective electrocardiographic (ECG) gating. The CT scan protocol depended on the clinical indications. Usually, scans were performed before pulmonary vein isolation. A typical protocol is described in the following. All patients hyperventilated before scanning. Then the scan was performed in inspiration during a single breath-hold. The scan extended from the supra-aortic region to the heart base, thus including parts of the thorax and upper abdomen into the field-of-view. The scan length ranged from 8 to $15 \mathrm{~cm}$, depending on the patient's stature. For CT, $80-100 \mathrm{~mL}$ iodinated contrast agent (Imeron 350 or 400, Bracco Imaging, Konstanz, Germany) was injected into an antecubital vein followed by a $40 \mathrm{ml}$ saline flush, both at a flow rate of $4 \mathrm{ml} / \mathrm{s}$. The scan was triggered by automated bolus tracking with the region-of-interest placed in the ascending aorta. The scan parameters were: Spiral scan, cranio-caudal direction, pitch $0.18-0.22$, detector collimation $64 \times 0.625 \mathrm{~mm}$, gantry rotation time $350 \mathrm{~ms}$, tube voltage $120 \mathrm{kV}$, maximum tube current $500 \mathrm{~mA}$, and using tube current modulation. Using retrospective ECG gating, CT slices with a thickness of $0.625 \mathrm{~mm}$ were reconstructed at $65-85 \%$ of the RR interval at increments of $5 \%$. In individual cases further cardiac phases were reconstructed for optimizing the image quality. Typical radiation dose parameters were a volume CT dose index $\left(\mathrm{CTDI}_{\mathrm{VOL}}\right)$ of $50 \mathrm{mGy}$ and dose length product (DLP) of 400-750 mGy $\times \mathrm{cm}$. With a conversion factor of 0.017 for the chest, the effective dose was about 6.8-12.8 mSv.

\section{Assessment of cardiac and extra-cardiac findings}

The cardiac CTs were independently reviewed by two radiologists and one cardiologist who were blinded to the clinical data, with disagreement solved in consensus. Axial and multiplanar CT images were viewed at standard window settings (lung, soft tissue, and bone windows) using a PACS system (Centricity Radiology RA 1000, GE Healthcare, Milwaukee, USA). First, all cardiac CT findings were analyzed and recorded, e.g. coronary artery stenoses or pulmonary vein variations. Then extra-cardiac CT findings were searched, including pulmonary, osseous, abdominal and soft tissue abnormalities. These extra-cardiac findings were clas- 
sified into "significant" and "non-significant", similar to previous studies [10,11, 13-15]. An extra-cardiac finding was classified as "significant", if it could change patient management due to subsequent diagnostics and/or therapy. Otherwise, an extra-cardiac finding was classified as "non-significant". The "significant" findings included newly detected cancer, enlarged lymph nodes sizing $>10 \mathrm{~mm}$, severe lung emphysema, and others. The "nonsignificant" findings included mild degenerative spine disease, small lymph nodes $<10 \mathrm{~mm}$, unspecific pulmonary scars, and others. There was no comparison with prior imaging findings for both, cardiac and extra-cardiac findings.

\section{Pulmonary vein isolation}

The subsequent pulmonary vein isolation was performed using the high-resolution CT images and electroanatomical mapping with CARTO $^{\circledR}$ for three-dimensional mapping (CartoMerge XP, Biosense Webster, Diamond Bar, CA, USA), and circumferential ablation was performed for each vein ostium using an open-irrigated $3.5 \mathrm{~mm}$ ablation catheter (Navistar Thermocool, Biosense Webster, Diamond Bar, CA, USA).

\section{Additional diagnostics and costs}

The following diagnostics (CT, X-ray, ultrasound or MRI) to clarify "significant findings" were analyzed, and costs were calculated in detail using the basic single rates for one patient of the medical fee schedule in Germany 2012 [16].

\section{Results}

\section{Patients and CT indications}

Among the included 224 patients, $63 \%$ were male and $37 \%$ were female. The age of the patients was $64 \pm 10$ years (mean $\pm S D$; range 10 to 84 years). All patients had atrial fibrillation, and their cardiac CT was clinically indicated for the planning of pulmonary vein isolation (PVI). In 220 (98\%) patients this was the first ablation, and in 4 patients ( $2 \%$ ) this was a re-ablation after previous PVI (๑ Table 1$)$.

\section{Cardiac findings}

In $91 \%$ of patients (203 of 224), a total of 724 cardiac findings were identified ( $\bullet$ Table 2 ). Most common was coronary artery

Table 1 Patients and CT indications.

Tab. 1 Patienten, Risikofaktoren und CT-Indikationen,

\begin{tabular}{|lc|}
\hline descriptive statistics & \\
\hline patients, total & 224 \\
\hline age (mean \pm SD) & $64 \pm 10$ years \\
\hline male & $142(63 \%)$ \\
\hline female & $82(37 \%)$ \\
\hline cardiovascular risk factors & $224(100 \%)$ \\
\hline atrial fibrillation & $125(56 \%)$ \\
\hline hypertension & $112(50 \%)$ \\
\hline dyslipidemia & $85(38 \%)$ \\
\hline smoking & $44(20 \%)$ \\
\hline diabetes mellitus & \\
\hline indications for cardiac CT & $220(98 \%)$ \\
\hline status before PVI & $4(2 \%)$ \\
\hline status after prior PVI & \\
\hline
\end{tabular}

$\mathrm{PVI}=$ pulmonary vein isolation
Table 2 Cardiac findings.

Tab. 2 Kardiale Befunde.

\begin{tabular}{|c|c|c|c|}
\hline location & cardiac findings & patients & percent \\
\hline \multirow[t]{5}{*}{ atrial } & left atrial dilatation ${ }^{1}$ & 40 & $5.5 \%$ \\
\hline & right atrial dilatation ${ }^{1}$ & 40 & $5.5 \%$ \\
\hline & intima flap of the atrial septum & 16 & $2.2 \%$ \\
\hline & cardiac aneurysm right atrium & 1 & $0.1 \%$ \\
\hline & left atrial scar & 1 & $0.1 \%$ \\
\hline \multirow[t]{2}{*}{ thrombus } & thrombus left atrium ${ }^{2}$ & 13 & $1.8 \%$ \\
\hline & thrombus left ventricle ${ }^{2}$ & 1 & $0.1 \%$ \\
\hline \multirow[t]{5}{*}{ ventricle } & right ventricular dilatation ${ }^{1}$ & 11 & $1.5 \%$ \\
\hline & left ventricular dilatation ${ }^{1}$ & 3 & $0.4 \%$ \\
\hline & left ventricular hypertrophy ${ }^{1}$ & 5 & $0.7 \%$ \\
\hline & right ventricular hypertrophy ${ }^{1}$ & 1 & $0.1 \%$ \\
\hline & cardiac aneurysm left ventricle & 1 & $0.1 \%$ \\
\hline \multirow{3}{*}{$\begin{array}{l}\text { pulmonary } \\
\text { artery }\end{array}$} & pulmonary artery dilatation ${ }^{1}$ & 12 & $1.7 \%$ \\
\hline & pulmonary artery hypoplasia & 1 & $0.1 \%$ \\
\hline & pulmonary artery stenosis & 1 & $0.1 \%$ \\
\hline \multirow[t]{5}{*}{ aortic } & $\begin{array}{l}\text { aortic arteriosclerosis } \\
\text { (moderate or severe) }\end{array}$ & 50 & $6.9 \%$ \\
\hline & aortic valve sclerosis & 29 & $4.0 \%$ \\
\hline & aortic valve replacement & 2 & $0.3 \%$ \\
\hline & aortic and pulmonary stents & 3 & $0.4 \%$ \\
\hline & $\begin{array}{l}\text { aortic stenosis }>50 \% \\
\text { (including coarctation) }\end{array}$ & 3 & $0.4 \%$ \\
\hline \multirow[t]{5}{*}{ mitral } & mitral valve sclerosis & 19 & $2.6 \%$ \\
\hline & mitral valve replacement & 4 & $0.6 \%$ \\
\hline & mitral anulus dilatation ${ }^{1,2}$ & 1 & $0.1 \%$ \\
\hline & mitral valve anuloplastia & 1 & $0.1 \%$ \\
\hline & endocarditis ${ }^{2}$ & 1 & $0.1 \%$ \\
\hline tricuspidal & tricuspidal valve replacement & 1 & $0.1 \%$ \\
\hline \multirow[t]{2}{*}{ vena cava } & inferior vena cava dilatation $>4 \mathrm{~cm}$ & 2 & $0.3 \%$ \\
\hline & superior vena cava dilatation $>4 \mathrm{~cm}$ & 1 & $0.1 \%$ \\
\hline \multirow[t]{2}{*}{ septal } & thin septum (ventricular) ${ }^{1}$ & 4 & $0.6 \%$ \\
\hline & septal hypertrophy $>2 \mathrm{~cm}$ (ventricular) & 3 & $0.4 \%$ \\
\hline \multirow[t]{5}{*}{ RCA } & RCA sclerosis (1-49\% luminal reduction) & 50 & $6.9 \%$ \\
\hline & RCA stenosis ( $\geq 50 \%$ luminal reduction) & 20 & $2.8 \%$ \\
\hline & coronary anomaly & 10 & $1.4 \%$ \\
\hline & coronary stent & 11 & $1.5 \%$ \\
\hline & coronary bypass & 15 & $2.1 \%$ \\
\hline \multirow[t]{2}{*}{ LM } & LM sclerosis ( $1-49 \%$ luminal reduction) & 35 & $4.8 \%$ \\
\hline & LM stenosis ( $\geq 50 \%$ luminal reduction) & 4 & $0.6 \%$ \\
\hline \multirow[t]{2}{*}{ LAD } & LAD sclerosis (1-49\% luminal reduction) & 89 & $12.3 \%$ \\
\hline & LAD stenosis ( $\geq 50 \%$ luminal reduction) & 30 & $4.1 \%$ \\
\hline \multirow[t]{2}{*}{ LCX } & LCX sclerosis (1-49\% luminal reduction) & 54 & $7.5 \%$ \\
\hline & LCX stenosis ( $\geq 50 \%$ luminal reduction) & 17 & $2.3 \%$ \\
\hline \multirow{6}{*}{$\begin{array}{l}\text { pulmonary } \\
\text { vein }\end{array}$} & common left pulmonary vein ostium & 37 & $5.1 \%$ \\
\hline & pulmonary vein dilatation & 6 & $0.8 \%$ \\
\hline & pulmonary vein stenosis & 11 & $1.5 \%$ \\
\hline & common right pulmonary vein ostium & 7 & $1.0 \%$ \\
\hline & three/accessory pulmonary veins right & 12 & $1.7 \%$ \\
\hline & three/accessory pulmonary veins left & 1 & $0.1 \%$ \\
\hline \multirow[t]{3}{*}{ pericardial } & pericardial effusion (clinically relevant) & 13 & $1.8 \%$ \\
\hline & pericardial sclerosis & 7 & $1.0 \%$ \\
\hline & pericardial lipomatosis & 2 & $0.3 \%$ \\
\hline \multirow{3}{*}{$\begin{array}{l}\text { interven- } \\
\text { tional }\end{array}$} & status after cardiac puncture & 18 & $2.5 \%$ \\
\hline & $\begin{array}{l}\text { status after dislocation of } \\
\text { pacemaker wire }\end{array}$ & 3 & $0.4 \%$ \\
\hline & $\begin{array}{l}\text { status after perforation of } \\
\text { pacemaker wire }\end{array}$ & 1 & $0.1 \%$ \\
\hline findings, tc & & 724 & $100 \%$ \\
\hline
\end{tabular}

$\mathrm{RCA}=$ right coronary artery; $\mathrm{LM}=$ left main artery; $\mathrm{LAD}=$ left anterior descending;

LCX = left circumflex artery

${ }^{1}$ Adapted from Lang et al. [31].

${ }^{2}$ Consistent with findings from echocardiography. 
sclerosis with $1-49 \%$ luminal reduction ( $<50 \%=$ sclerosis) of the LAD (left anterior descending coronary artery) in 89 cases (12.3\%), of the LCX (left circumflex artery) in 54 cases (7.5\%), of the RCA (right coronary artery) in 50 cases (6.9\%), and of the LM (left main coronary artery) in 35 cases (4.8\%). Coronary stenosis with $\geq 50 \%$ luminal reduction was found in the RCA (20 cases; $2.8 \%$ ), LM (4 cases; 0.6\%), LAD (30 cases; $4.1 \%$ ), and LCX (17 cases; $2.3 \%$ ). On average there were 3.2 cardiac findings per patient.

\section{Extra-cardiac findings}

In $80 \%$ of patients ( 179 of 224 ) a total of 619 extra-cardiac findings were identified. Among them, 32\% (196 of 619) were classified as "significant" ( $\bullet$ Table 3 ) and $68 \%$ (423 of 619) as "non-significant" ( $\bullet$ Table 4$)$.

The most frequent "significant" extra-cardiac findings were: $7.3 \%$ (45 of 619 cases) with clinically symptomatic extensive degenerative spine disease, $5.8 \%$ (36 of 619 cases with additional follow-up such as X-ray) with enlarged mediastinal/hilar lymph nodes sizing $>10 \mathrm{~mm}$, and $4.2 \%$ ( 26 of 619 cases) with moderate to severe lung emphysema (follow-up for this disease with chest$\mathrm{CT}$ ). Among the less frequent but clinically important "significant" extra-cardiac findings were: aortic ectasia or aneurysm of $>4 \mathrm{~cm}$ diameter (10 patients), primary diagnosis of pneumonia (2 patients), primary diagnosis of pulmonary embolism (1 patient), primary diagnosis of aortic dissection (1 patient), previously unknown esophageal cancer ( 1 patient), and previously unknown lung cancer (1 patient).

The most frequent "non-significant" extra-cardiac findings were: $19.1 \%$ (118 of 619 cases) with asymptomatic mild degenerative spine diseases, $13.1 \%$ (81 of 619) with pulmonary scars, and $5.5 \%$ (34 of 619 cases) with prominent mediastinal or hilar lymph nodes sizing 8-10 $\mathrm{mm}$ (but not exceeding $10 \mathrm{~mm}$ diameter).

Table 3 Significant extra-cardiac findings.

Tab. 3 Signifikante extra-kardiale Befunde.

\begin{tabular}{|c|c|c|c|}
\hline location & significant extra-cardiac findings & count & percent \\
\hline \multirow[t]{2}{*}{ vascular } & aortic ectasia or aneurysm $>4 \mathrm{~cm}$ & 10 & $1.6 \%$ \\
\hline & aortic dissection & 1 & $0.2 \%$ \\
\hline mediastinal & $\begin{array}{l}\text { mediastinal/hilar lymph nodes } \\
>10 \mathrm{~mm}\end{array}$ & 36 & $5.8 \%$ \\
\hline \multirow[t]{10}{*}{ pulmonary } & moderate/severe lung emphysema & 26 & $4.2 \%$ \\
\hline & pulmonary fibrosis & 17 & $2.7 \%$ \\
\hline & pulmonary nodule $>10 \mathrm{~mm}$ & 20 & $3.2 \%$ \\
\hline & pneumonia & 4 & $0.6 \%$ \\
\hline & ground glass attenuation & 4 & $0.6 \%$ \\
\hline & pneumokoniosis or asbestosis & 2 & $0.3 \%$ \\
\hline & lung cancer & 1 & $0.2 \%$ \\
\hline & pulmonary embolism & 1 & $0.2 \%$ \\
\hline & pulmonary cavern (or bulla) & 1 & $0.2 \%$ \\
\hline & air space opacity & 1 & $0.2 \%$ \\
\hline \multirow[t]{3}{*}{ osseous } & extensive degenerative spine disease & 45 & $7.3 \%$ \\
\hline & rib lesion & 5 & $0.8 \%$ \\
\hline & fracture of thoracic vertebra & 1 & $0.2 \%$ \\
\hline \multirow[t]{2}{*}{ diaphragmal } & diaphragmatic hernia $>2 \mathrm{~cm}$ & 14 & $2.3 \%$ \\
\hline & esophageal cancer & 1 & $0.2 \%$ \\
\hline \multirow[t]{3}{*}{ abdominal } & epigastric lymph nodes & 3 & $0.5 \%$ \\
\hline & unclear liver lesion & 2 & $0.3 \%$ \\
\hline & splenomegaly & 1 & $0.2 \%$ \\
\hline findings, total & & 196 & $\begin{array}{l}31.7 \% \\
\text { of } n=619\end{array}$ \\
\hline
\end{tabular}

\section{Examples and Summary of Findings}

- Fig. 1-4 show some typical examples of significant and nonsignificant extra-cardiac and cardiac findings. On average there were 3.2 cardiac and 2.8 extra-cardiac findings per patient, with $32 \%$ of all extra-cardiac findings classified as potentially "significant" for patient management ( $\bullet$ Table 5 ). There were significantly more extra-cardiac findings in patients with a pathological cardiac finding, in patients over 60 years of age, and in patients with a history of smoking $(P<0.05)$. Smokers also had significantly more pathological cardiac findings than non-smokers $(P<0.05)$.

\section{Additional diagnostics and costs}

Many patients received follow-up diagnostics for evaluating incidental "significant" extra-cardiac findings, causing subsequent costs. In the German public healthcare system, a CT scan costs

Table 4 Non-significant extra-cardiac findings.

Tab. 4 Nicht-signifikante extra-kardiale Befunde.

\begin{tabular}{|c|c|c|c|}
\hline location & non-significant extra-cardiac findings & count & percent \\
\hline \multirow[t]{4}{*}{ vascular } & aortic ectasis $<4 \mathrm{~cm}$ & 5 & $0.8 \%$ \\
\hline & lusoria artery & 1 & $0.2 \%$ \\
\hline & accessory hepatic artery & 1 & $0.2 \%$ \\
\hline & $\begin{array}{l}\text { common ostium of left subclavian and } \\
\text { vertebral artery }\end{array}$ & 1 & $0.2 \%$ \\
\hline mediastinal & $\begin{array}{l}\text { mediastinal/hilar lymph nodes sizing } \\
8-10 \mathrm{~mm}\end{array}$ & 34 & $5.5 \%$ \\
\hline \multirow[t]{10}{*}{ pulmonary } & pulmonary scar & 81 & $13.1 \%$ \\
\hline & bronchial thickening & 21 & $3.4 \%$ \\
\hline & pulmonary bulla & 15 & $2.4 \%$ \\
\hline & asymptomatic lung emphysema & 11 & $1.8 \%$ \\
\hline & atelectasis & 11 & $1.8 \%$ \\
\hline & focal bronchitis with tree-in-bud & 8 & $1.3 \%$ \\
\hline & bronchiectasis & 8 & $1.3 \%$ \\
\hline & pulmonary granuloma $<10 \mathrm{~mm}$ & 6 & $1.0 \%$ \\
\hline & $\begin{array}{l}\text { pulmonary nodule }<10 \mathrm{~mm} \\
\text { (e. g. calcification) }\end{array}$ & 3 & $0.5 \%$ \\
\hline & small and linear lung opacity & 1 & $0.2 \%$ \\
\hline \multirow[t]{3}{*}{ pleural } & pleural sclerosis & 9 & $1.5 \%$ \\
\hline & pleural effusion & 7 & $1.1 \%$ \\
\hline & pleural thickening & 2 & $0.3 \%$ \\
\hline \multirow[t]{8}{*}{ chest wall } & $\begin{array}{l}\text { cardiac devices other than pacemakers } \\
\text { (intracardiac defibrillator, event } \\
\text { recorder) }\end{array}$ & 31 & $5.0 \%$ \\
\hline & status after sternotomy & 13 & $2.1 \%$ \\
\hline & cardiac pacemaker & 3 & $0.5 \%$ \\
\hline & lipoma & 1 & $0.2 \%$ \\
\hline & pectus excavatum & 1 & $0.2 \%$ \\
\hline & ablation of the breasts & 1 & $0.2 \%$ \\
\hline & extended relaxed diaphragm & 1 & $0.2 \%$ \\
\hline & thoracic collateral veins dilatation & 1 & $0.2 \%$ \\
\hline \multirow[t]{4}{*}{ osseous } & $\begin{array}{l}\text { asymptomatic mild degenerative spine } \\
\text { disease }\end{array}$ & 118 & $19.1 \%$ \\
\hline & thoracic spine hemangioma & 2 & $0.3 \%$ \\
\hline & rib osteoma & 1 & $0.2 \%$ \\
\hline & rib cysts & 1 & $0.2 \%$ \\
\hline \multirow[t]{5}{*}{ abdominal } & hepatic cysts & 14 & $2.3 \%$ \\
\hline & hepatic hemangioma & 5 & $0.8 \%$ \\
\hline & ascites & 3 & $0.5 \%$ \\
\hline & accessory spleen & 1 & $0.2 \%$ \\
\hline & hepatic steatosis & 1 & $0.2 \%$ \\
\hline total & all & 423 & $\begin{array}{l}68.3 \% \\
\text { of } n=619\end{array}$ \\
\hline
\end{tabular}




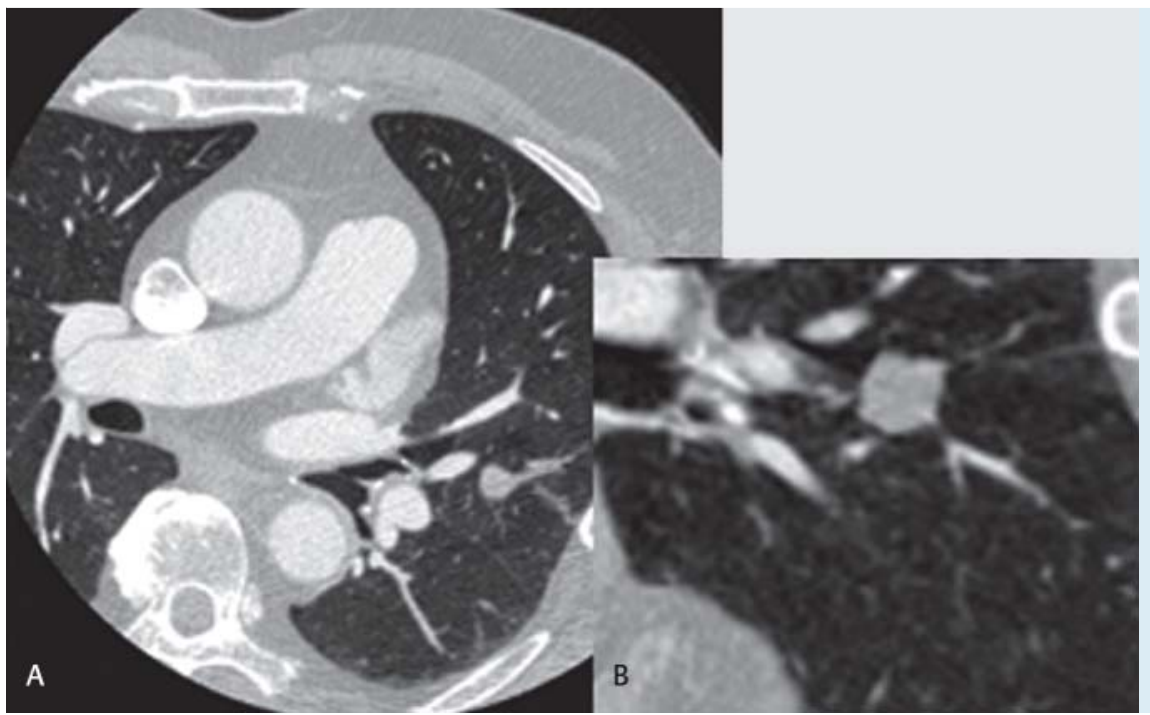

Fig. 1 Pulmonary granuloma in a 60-year-old patient of the left upper lung ( $>4 \mathrm{~mm}$ diameter). After the primary cardiac $\mathrm{CT}$ scan, the diagnosis was not clear, and therefore we considered this finding as "significant" extra-cardiac structure and recommended follow-up and further diagnostics. The final diagnosis of granuloma was based on follow-up CT and bronchoscopy ( $\mathbf{A}$ axial view, contrast-enhanced 64-slice MDCT; $\mathbf{B}$ magnification of A).

Abb. 1 Pulmonales Granulom bei einem 60-jährigen Patienten, welches im Cardio-CT zufällig im linken Oberlappen gefunden wurde ( $>4 \mathrm{~mm}$ ). Nach dem ersten CT war der Befund nicht eindeutig, sodass zusätzliche Untersuchungen empfohlen wurden. Somit wurde der Befund als „signifikant“ bezeichnet. Die finale Diagnose wurde mit der Hilfe einer Bronchoskopie gestellt (A axial, kontrastmittelgestützte 64-Zeilen MDCT; B Vergrößerung von $\mathbf{A}$ ).

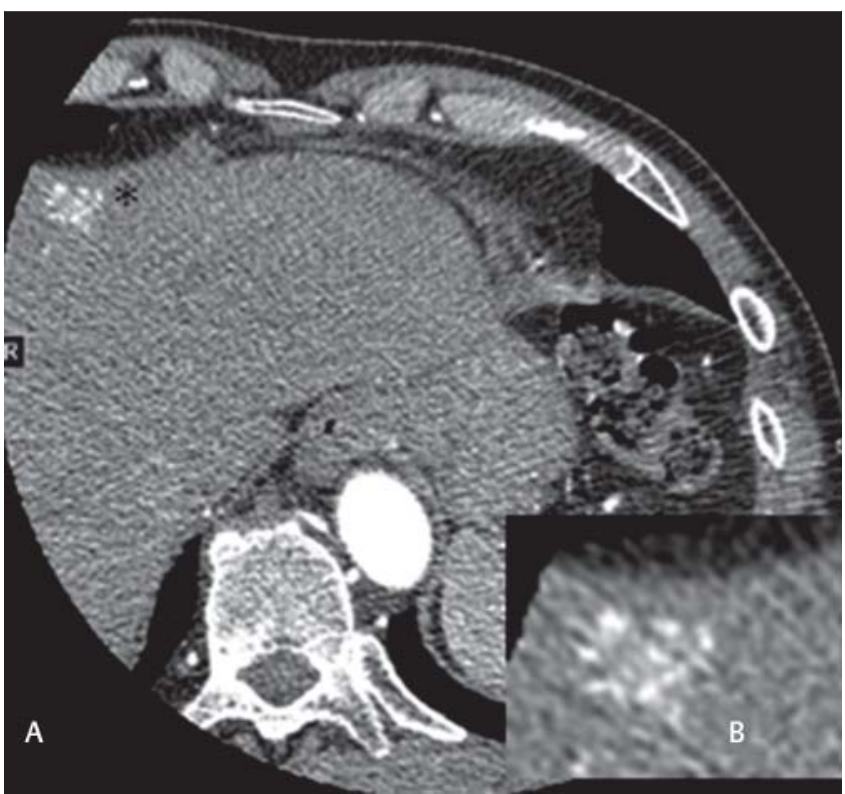

Fig. 2 A 72-year-old male with atrial fibrillation and coronary artery disease was seen with a subcapsular hepatic hemangioma of the right hepatic lobe at the border of the FOV. The diagnosis was made by the first CT scan and there was no recommendation for further diagnostics (A axial view; B magnification; both with contrast medium, 64-slice MDCT). This extra-cardiac finding was previously unknown, but with no consequence in the patient's management or additional diagnostics and therefore defined as "non-significant".

Abb. 2 Bei einem 72-jährigen Patienten mit Vorhofflimmern und Koronarer Herzkrankeit fanden wir ein subkapsuläres Hämangiom im rechten Leberlappen am Rand des FOVs. Die Diagnose war nach dem ersten CT eindeutig und es gab keine Indikation für weitere Untersuchungen ( $\mathbf{A}$ axial; B Vergrößerung; kontrastmittelgestützte 64-Zeilen MDCT). Dieser Befund war vorher unbekannt, hatte keine Konsequenzen für die Therapie des Patienten bzw. weiterführende Diagnostik und wurde somit als „nicht-signifikant" definiert.

151.55 Euros (additional costs were 46.63 Euros for 3D reconstruction and 29.14 Euros for additional series) [16]. The costs for contrast medium in CT were 5.95 in one patient. Within the study group there were additional total costs for CT of 28925.48 Euros (approximately 38314.69 US dollars) in a total of 124 patients.

Ultrasound costs 11.66 Euros for one organ, and ultrasound of three more organs costs an additional 4.66 Euros. The total costs for all ultrasound examinations in 19 patients were 310.08 Euros (approximately 410.73 US dollars).

The costs for a single abdominal MRI were 256.46 Euros (additional costs were 17.49 Euros for injections of contrast medium, 58.49 Euros for additional series or 1.75 Euros for placing of an intravenous line). The costs for contrast medium were about 25.70 Euros for abdominal MRI, e. g. using $10 \mathrm{ml}$ gadobutrol. The total costs for additional MRI in 4 patients were 1439.56 Euros (approximately 1906.84 US dollars).

A chest X-ray costs 26.23 Euros for different planes (e.g. posterior-anterior and lateral plane). The total costs for an additional chest X-ray in 55 patients were 1442.65 Euros (about 1910.93 US dollars).

We did not calculate the costs for additional interventions such as catheter-based angiography or biopsy under CT or ultrasound guidance. When including these diagnostics, the total costs for follow-up imaging of "significant" extra-cardiac findings are accordingly higher. Such additional costs comprise anesthesia, consumption of further material, room/staff costs, or a patient's hospital stay (basic single rates for patients of the medical fee schedule in Germany 2012) [16]. Altogether, the additional costs for these subsequent diagnostics in our study (without intervention or biopsy) were about 32117.77 Euros (about 42 543.19 US dollars, based on the exchange rate on July 25, 2013).

\section{Discussion \\ $\nabla$}

\section{Statement of principal findings}

This study showed that extra-cardiac incidental findings are common in clinically indicated cardiac CT before pulmonary vein isolation. On average there were 3.2 cardiac and 2.8 extracardiac findings per patient, with $32 \%$ of all extra-cardiac findings classified as potentially "significant" for patient management. These findings included two patients with primarily detected cancer, who were treated accordingly, 10 patients with aortic aneurysm/ectasia, and one patient with primarily detected aortic dissection. 

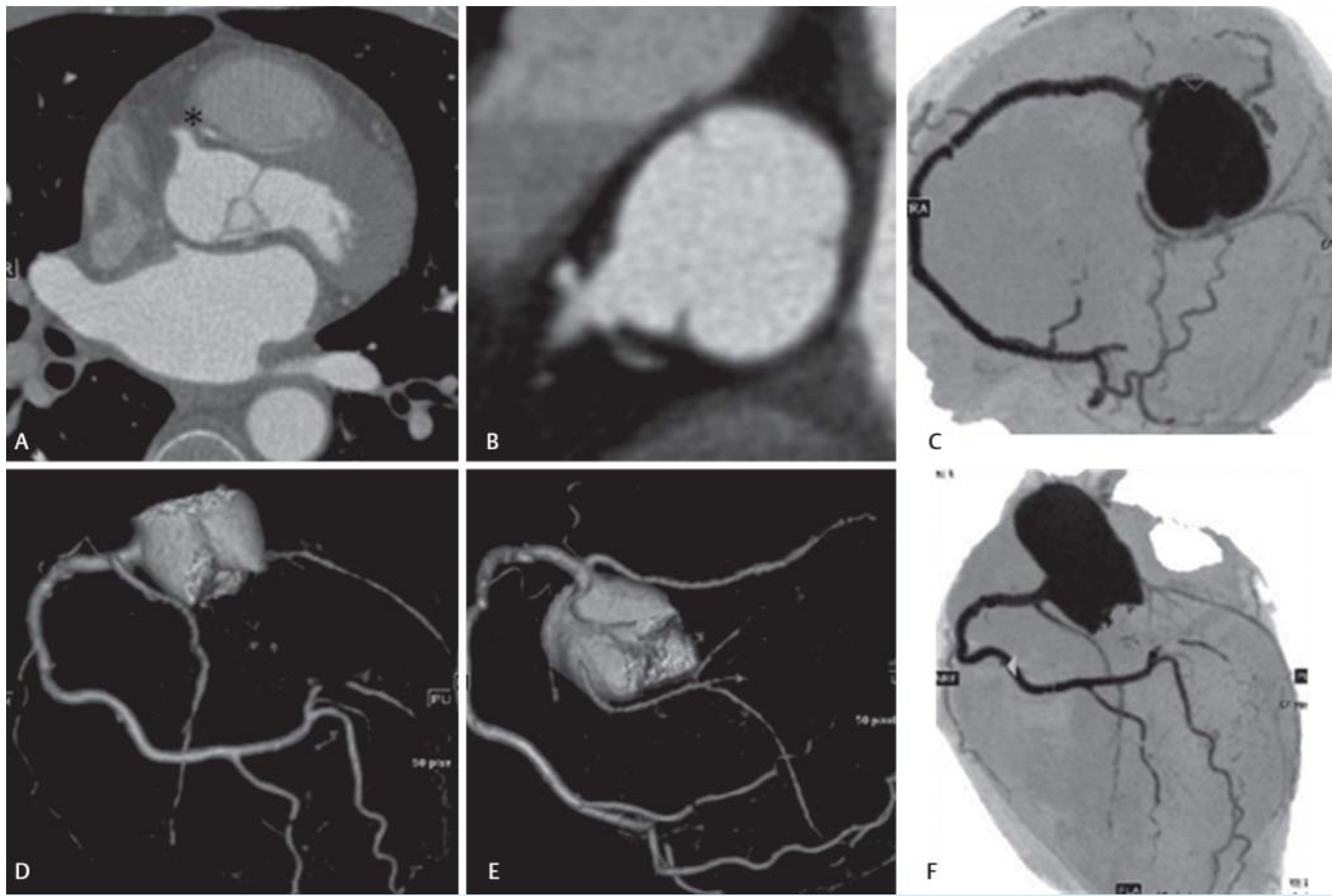

Fig. 3 In a 60-year-old female, we detected an ectopic pathway of the LAD originating from the RCA $\mathbf{A}^{*}$. The LAD route passed between the ascending aorta and pulmonary trunk $\mathbf{B}-\mathbf{F}$. Thus, this cardiac status was defined as a malignant coronary anomaly (A, B axial views; both contrast-enhanced 64-slice MDCT; $\mathbf{D}$, E were $3 \mathrm{D}$ reconstructions and $\mathbf{C}$, $\mathbf{F}$ subtraction images) and defined as a "significant" cardiac finding that was previously unknown and detected on the cardiac CT scan.

Abb.3 Bei einer 60-jährigen Patientin zeigte sich ein ektoper Verlauf des Ramus interventricularius anterior (RIVA) aus der rechten Koronararterie $\mathbf{A}^{*}$. Der RIVA verläuft zwischen der Aorta ascendens und dem Truncus pulmonalis B-F. Dieser kardiovaskuläre Befund wurde als maligne Koronaranomalie bezeichnet (A, B axial; kontrastmittelgestützte 64-Zeilen MDCT; D, E 3D-Rekonstruktionen und C, F Subtraktionsbilder) und wurde als ein „signifikanter" Befund definiert, der vorher nicht bekannt war und im CT erstmalig festgestellt wurde.
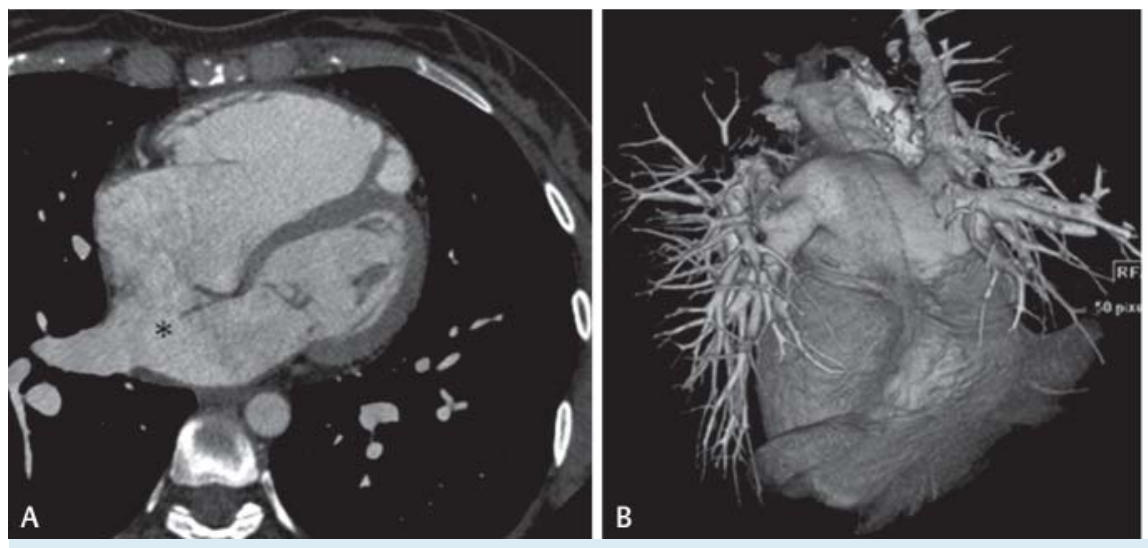

Fig. 4 In a 37-year-old female, we primarily observed an atrial septal defect $\left({ }^{*} \mathbf{A}\right.$ axial view, contrast-enhanced 64 -slice MDCT, confirmed by echocardiography). Besides, the right upper pulmonary drained into the right atrium (isolated partial anomalous pulmonary venous return). Due to the associated increased pulmonary flow, the right heart was dilated. The 3D reconstruction and dorsal heart view demonstrated a common pulmonary venous ostium on the right side into the atrium (B 3 D 64-slice MDCT). These findings were defined as "significant" cardiac findings and were confirmed by echocardiography.
Abb.4 Bei einer 37-jährigen Patientin zeigte sich ein atrialer Septumdefekt ( ${ }^{*} \mathbf{A}$ axial, kontrastmittelgestützte 64-Zeilen MDCT, mit Echokardiografie bestätigt). Zusätzlich mündete die rechte obere Pulmonalvene in den rechten Vorhof (partielle Lungenvenenfehlmündung vom kardialen Typ). Bei entsprechend vermehrter Perfusion im Lungenkreislauf bestand eine Rechtsherzvergrößerung. Die 3D-Rekonstruktion und dorsale Herzansicht zeigte ein gemeinsames Pulmonalvenenostium auf der rechten Seite in den Vorhof (B 3 D 64-Zeilen MDCT). Diese Befunde wurden als "signifikant" bezeichnet und mit der Echokardiografie bestätigt. 
Table 5 Summary of cardiac and extra-cardiac findings.

Tab.5 Zusammenfassung der kardialen und extra-kardialen Befunde.

\begin{tabular}{|lrr|} 
& count & percent \\
\hline patients, total & 224 & $100 \%$ \\
\hline patients with cardiac findings & 203 & $91 \%$ \\
\hline patients without cardiac findings & 21 & $9 \%$ \\
\hline patients with extra-cardiac findings & 179 & $80 \%$ \\
\hline patients without extra-cardiac findings & 45 & $20 \%$ \\
\hline cardiac findings, total & 724 & $100 \%$ \\
\hline extra-cardiac findings, total & 619 & $100 \%$ \\
\hline significant extra-cardiac findings & 196 & $32 \%$ \\
\hline non-significant extra-cardiac findings & 423 & $68 \%$ \\
\hline
\end{tabular}

Relevance of the study findings with comparison to the literature

In addition to the evaluation of cardiac anatomy and pulmonary vein status, surrounding cardiac and extra-cardiac structures could be included in examinations after the first scan due to the wide field-of-view surrounding the heart [17 - 19]. Several cardiac and extra-cardiac findings were described after cardiac-specific CT examination studies and were subdivided into significant or non-significant $[11,14,15]$. In 179 of the 224 patients $(80 \%)$, one or more incidental extra-cardiac findings were noted per patient. This is consistent with the literature in which the percentage of extra-cardiac findings at cardiac $\mathrm{CT}$ ranges from $8 \%$ in asymptomatic patients [10] to $69 \%$ in symptomatic patients [12] with known or suspected CAD.

In our study we observed a relatively high incidence of extra-cardiac and cardiac findings, which may be due to the detailed image and the advanced mean age of our patients. We did not scan healthy patients, patients from the emergency room or "outpatients". Our patients were pre-therapeutic "inpatients" with a specific disease (atrial fibrillation prior to PVI).

Many of our extra-cardiac findings did not cause a change in patient management. However, a considerable number of "significant" extra-cardiac findings were potentially relevant from a prospective perspective, or definitely caused a change of therapy. In more detail, $32 \%$ of all incidental extra-cardiac findings in our study were of clinical or therapeutic relevance and required additional diagnostics or further diagnostics. For comparison, in the study of Onuma et al. $22 \%$ of findings required follow-up and were therefore defined as "significant" findings [11].

In cardiac CT it is important to have a large field-of-view (FOV) to detect potential malignant findings that could potentially be treated at an early stage, such as peripheral lung cancer. Otherwise, with a small FOV focused on the heart, such findings could be missed with a severe impact on the patient's health $[20,21]$. However, additional findings result in additional diagnostics, work-up, and costs for the healthcare system [22]. Lee et al. demonstrated the prevalence of extra-cardiac findings in one-third of 151 patients with cardiac CT and calculated 438 US dollars per patient with follow-up diagnostics and an average of 17 US dollars per patient in the whole screening group [22]. In our study the average costs for follow-up diagnostics "significant" extracardiac findings were about 190 US dollars per patient for the whole study group (224 patients). The discussion about extra-focal findings next to the primarily focused region-of-interest is widespread and is not limited to the cardiac-thoracic region. For instance, many incidental findings are in the abdominal pelvic re- gion, as seen in a group of 1426 imaging studies by Orme et al. [23]. 576 (39\%) had an incidental finding, more often seen in elderly patients similar to our study results. A clear medical benefit was only seen in $1.1 \%$ of cases, i. e. in 6 of 567 patients. There was also a high incidence of unclear benefit, limited follow-up period and different imaging methods applied [23].

The cardiac CT imaging protocol usually includes parts of the lungs, spine and upper abdomen. It could be a risk not to evaluate them, when considering potential malignant findings: We found one lung cancer and one esophagus cancer that were confirmed by subsequent diagnostics (no metastasis, local stage). These cancers were seen in two patients of $224(0.89 \%)$ and were unknown before CT. For comparison, Hunold et al. found three lung cancers among 1812 patients [13] and Kanawo et al. detected four lung cancers, two thyroid cancers and one hepatic cancer among 625 patients [24]. Kim et al. found a prevalence of lung cancer after cardiac CT of $0.31 \%$, $68 \%$ of these malignancies were at a resectable stage [25].

Three studies analyzed the incidence of incidental findings before pulmonary vein isolation during the last years $[12,15,26]$. Schietinger et al. found $69 \%$, Wissner $53 \%$ and Martins $23.2 \%$ incidental findings in their patient cohort $[12,15,26]$. These values are in the range of former CT studies for CAD detection as described before [10,11]. All those studies differ with respect to patient number and median age. There are also differences regarding patient history and characteristics. In general, findings with a major impact on life quality and life expectancy are relatively rare, but in the affected patients the impact of such findings is strong, so that their detection is relevant.

The detection of such findings requires specific education in cardio-thoracic imaging pathology beyond the image interpretation of the heart in order to interpret cardiac CT images comprehensively. Clinical experience plays a further role. For example, long-term experienced cardio-thoracic radiologists detect and interpret incidental findings more precisely than less experienced colleagues [27]. A further question is how to cope with potentially malignant findings that are unexpected and require further diagnostics for confirming or excluding malignancy. In the patient's interest such findings should be reported for performing further diagnostic work-up [28]. On the one hand precise diagnostics, on the other hand balanced communication with the patient are necessary.

\section{Study limitations}

Our study is limited by the fact that it was performed retrospectively in a single center. The follow-up period should actually comprise a longer time span and more patients should be analyzed in a multi-center study. The study was performed in patients with atrial fibrillation before PVI and is therefore representative for such patients. However, studies with other patient characteristics may show somewhat different results. This study did not compare the success rate of cardiologists versus radiologists in detecting and interpreting cardiac and extra-cardiac CT findings. Instead we applied the consensus decision of two radiologists and one cardiologist in an interdisciplinary approach to cardiovascular imaging.

\section{Conclusion}

$\nabla$

This study has analyzed both cardiac and extra-cardiac findings in patients with atrial fibrillation and indication for pulmonary 
vein isolation. On the one hand there were 3.2 cardiac findings per patient. On the other hand there were even 2.8 extra-cardiac findings which had to be analyzed comprehensively and occur significantly more often in patients over 60 years old, in smokers and in patients with a history of cardiac findings ( $p<.05)$. Cardiac findings on CT are common in patients referred to CT with the mentioned risk factors (38\% smokers, $98 \%$ before pulmonary vein isolation and $2 \%$ after). Most findings can be diagnosed after the first examination, and others require further interdisciplinary diagnostics with consecutive costs (about 190 US dollars per patient). Radiologists and cardiologists have to be aware of relevant cardiac findings that need additional diagnostics or treatment as well as of extra-cardiac findings that might be relevant ( $32 \%$ ), require further diagnostics, and may change the individual outcome. We support the comprehensive integration of extracardiac findings into approved guidelines and into the teaching of cardiovascular imaging [29-34]. The evaluation of extra-cardiac findings on cardiac CT has important implications and cardiac anatomy is becoming an increasingly common indication for CT. Protocols and image analysis should be optimized for the identification of important incidental findings.

\section{References}

1 Raff GL, Gallagher MJ, O'Neill WW et al. Diagnostic accuracy of noninvasive coronary angiography using 64-slice spiral computed tomography. J Am Coll Cardiol 2005; 46: 552 - 557

2 Kuettner A, Kopp AF, Schroeder S et al. Diagnostic accuracy of multidetector computed tomography coronary angiography in patients with angiographically proven coronary artery disease. J Am Coll Cardiol 2004; 43: 831 - 839

3 Lessick J, Mutlak D, Rispler S et al. Comparison of multidetector computed tomography versus echocardiography for assessing regional left ventricular function. Am J Cardiol 2005; 96: 1011 - 1015

4 Raman SV, Cook SC, McCarthy B et al. Usefulness of multidetector row computed tomography to quantify right ventricular size and function in adults with either tetralogy of Fallot or transposition of the great arteries. Am J Cardiol 2005; 95: 683-686

5 Wood MA, Wittkamp M, Henry D et al. A comparison of pulmonary vein ostial anatomy by computerized tomography, echocardiography, and venography in patients with atrial fibrillation having radiofrequency catheter ablation. Am J Cardiol 2004; 93: 49-53

6 Jongbloed MR, Dirksen MS, BaxJJ et al. Atrial fibrillation: Multi-detector row CT of pulmonary vein anatomy prior to radiofrequency catheter ablation-initial experience. Radiology 2005; 34: 702 - 709

7 Takakuwa KM, Halpern EJ. Evaluation of a "triple rule-out" coronary CT angiography protocol: Use of 64-section CT in low-to-moderate risk emergency department patients suspected of having acute coronary syndrome. Radiology 2008; 248: 438 (436)

8 Manghat NE, Morgan-Hughes GJ, Roobottom CA. Multi-detector row computed tomography: Imaging in acute aortic syndrome. Clin Radiol 2005; 60: 1256-1267

9 Schoepf UJ, Goldhaber SZ, Costello P. Spiral computed tomography for acute pulmonary embolism. Circulation 2004; 109: 2160-2167

10 Horton KM, Post WS, Blumenthal RS et al. Prevalence of significant noncardiac findings on electron-beam computed tomography coronary artery calcium screening examinations. Circulation 2002; 106: $532-$ 534

11 Onuma $Y$, Tanabe K, Nakazawa G et al. Noncardiac findings in cardiac imaging with multidetector computed tomography. J Am Coll Cardiol 2006; 48: 402-406

12 Schietinger BJ, Bozlar U, Hagspiel KD et al. The prevalence of extra-cardiac findings by multidetector computed tomography before atrial fibrillation ablation. Am Heart J 2008; 155: 254-259

13 Hunold P, Schmermund A, Seibel RM et al. Prevalence and clinical significance of accidental findings in electronbeam tomographic scans for coronary artery calcification. Eur Heart J 2001; 22: 1748 - 1758
14 Schragin JG, Weissfeld JL, Edmundowicz D et al. Non-cardiac findings on coronary electron beam computed tomography scanning. J Thorac Imaging 2004; 19: 82 - 86

15 Martins RP, Muresan L, Sellal JM et al. Incidental extracradiac findings in cardiac computed tomography performed before radiofrequency ablation of atrial fibrillation. Pace 2011; 34: $1665-1670$

16 GOÄ 2012. Hermanns PM, Filler G, Roscher B (Hrsg) 6. Aufl. Berlin Heidelberg: Springer-Verlag; 2012; DOI: 10.1007/978-3-642257643_1

17 Kistler PM, Rajappan K, Harris S et al. The impact on image integration on catheter ablation of atrial fibrillation using electroanatomic mapping: A prospective randomized study. Eur Heart J 2008; 29: 30293036

18 de Chillou C, Adronache M, Abdelaal A et al. Evaluation of 3D guided electroanatomic mapping for ablation of atrial fibrillation in reference to CT-Scan image integration. J Interv Card Electropysiol 2008; 23: $175-181$

19 Martinek M, Nesser HJ, Aichinger J et al. Impact of integration of multislice computed tomography imaging into three-dimensional electroanatomic mapping on clinical outcome, safety, and efficacy using radiofrequency ablation for atrial fibrillation. Pacing Clin Electrophysiology 2007; 30: $1215-1223$

20 Johnson KM, Dennis JM, Dowe DA. Extracardiac findings on coronary CT angiograms: Limited versus complete image review. Am J Roentgenol 2010; $195: 143-148$

21 Northam M, Koonce J, Ravenel JG. Pulmonary nodules detected at cardiac CT: Comparison of images in limited and full fields of view. Am J Roentgenol 2008; 191: 878-881

22 Lee CI, Tsai EB, Sigal BM et al. Incidental extracardiac findings at coronary CT: Clinical and economic impact. Am J Roentgenol 2010; 194 $1531-1538$

23 Orme NM, Fletcher JG, Siddiki HA et al. Incidental findings in imaging research. Evaluating incidence, benefit, and burden. Arch Intern Med 2010; 170: 1525-1532

24 Kawano Y, Tamura A, Goto $Y$ et al. Incidental detection of cancers and other non-cardiac abnormailities on coronary multislice computed tomography. Am J Cardiol 2007; 99: 1608 - 1609

25 Kim TJ, Han DH, Jin KN et al. Lung cancer detected at cardiac CT: Prevalence, clinicoradiologic features, and importance of full-field-of-view images. Radiology 2010; 255: 369-376

26 Wissner E, Wellnitz CV, Srivathsan K et al. Value of multislice computed tomography angiography of the thorax in preparation for catheter ablation for the treatment of atrial fibrillation: The impact of unexpected cardiac and extracardiac findings on patient care. Eur J Radiol 2009; 72: $284-288$

27 Quint LE, Watcharotone K, Myles JD et al. Incidental findings at chest CT: A needs assessment survey of radiologists' knowledge. Acad Radiol 2011: $18: 1500-1506$

28 Wann S, Nassef AL, Jeffrey J et al. Ethical considerations in CT angiography. Int J Cardiovasc Imaging 2007; 23: 379-388

29 Mark DB, Berman DS, Budoff MJ. American College of Cardiology Foundation Task Force on Expert Consensus Documents. et al. ACCF/ACR/ AHA/NASCI/SAIP/SCAI/SCCT 2010 expert consensus document on coronary computed tomographic angiography: A report of the American College of Cardiology Foundation Task Force on Expert Consensus Documents. Catheter Cardiovasc Interv 2010; 76: E1 -E42

30 Earls JP. The pros and cons of searching for extracardiac findings at cardiac CT: Studies should be reconstructed in the maximum field of view and adequately reviewed to detect pathologic findings. Radiology 2011; 261: $342-346$

31 Fischbach R, Miller S, Beer $M$ et al. Empfehlungen der Arbeitsgemeinschaft Herzdiagnostik der Deutschen Röntgengesellschaft für den Einsatz der Computertomographie und Magnetresonanztomographie in der Herzdiagnostik. Teil 1 - Computertomographie. Rofo 2009; 181: $700-706$

32 Lang RM, Bierig M, Devereux RB et al. Recommendations for chamber quantification. Eur J Echocardiogr 2006; 7: 79-108

33 Jacobs PC, Mali WP, Grobbee DE et al. Prevalence of incidental findings in computed tomographic screening of the chest: a systematic review. J Comput Assist Tomogr 2008; 32: 214-221

34 Yorgun H, Kaya EB, Hazirolan $T$ et al. Prevalence of incidental pulmonary findings and early follow-up results in patients undergoing dual-source 64-slice computed tomography coronary angiography. J Comput Assist Tomogr 2010; 34: 296 - 301 